\title{
EL DISTRITO TURÍSTICO RURAL: MODELO DE DESARROLLO PARA EL CANTÓN PEDERNALES - PROVINCIA DE MANABÍ (ECUADOR)
}

\section{THE RURAL TOURISM DISTRICT: THE DEVELOPMENTMODEL FOR PEDERNALES - PROVINCE OF MANABÍ (ECUADOR)}

\author{
Giovanni Herrera Enríquez ${ }^{1}$ \\ gpherrera@espe.edu.ec \\ Fabricio Guevara Viejó ${ }^{2}$ \\ Sergio Castillo-Páez ${ }^{1}$ \\ Eddy Castillo Montesdeoca ${ }^{1}$ \\ 1 Universidad de las Fuerzas Armadas - ESPE, Ecuador. \\ 2 Universidad Estatal de Milagro, Ecuador.
}

\section{RESUMEN}

El turismo es una actividad dinamizadora de la economía que gestionada de una manera socialmente responsable logra la distribución equitativa de la riqueza. La propuesta del distrito turístico rural busca un equilibrio entre el bienestar de los territorios y la satisfacción de los turistas, una metodológica que incorpora herramientas de gestión empresarial y proyectos sociales con un modelo de generación de valor que permite identificar características esenciales que busca la demanda turística. A partir de un inventario turístico georeferenciado sobre la base cartográfica proporcionada por el Instituto Geográfico Militar, se determinan las características de cada lugar, tradición o evento que pueden ser considerados como un atractivo turístico, posterior a ello se realiza un análisis situacional aplicando la matriz FODA y se determina la viabilidad de los proyectos turísticos en base a la matriz marco lógico. El uso de matrices multicriterio permite la identificación de atractivos idóneos para el turismo rural y la teoría de lugar central permite la organización de estos atractivos en distritos. La investigación aporta como base en el proceso de reconstrucción del sector turístico en el cantón Pedernales, devastado por el terremoto del 16 de abril de 2016.

Palabras Clave: Turismo Rural, Análisis Multicriterio, Planificación económica, Clustering, Innovación

\begin{abstract}
Tourism is an activity that revitalizes the economy, if managed in a socially responsible manner achieves equitable distribution of wealth. The proposal of rural tourism district seeks a balance between the welfare of the territories and the satisfaction of tourists. It could be considered as a methodology that incorporates business management and social projects tools with a value creation model that identifies essential characteristics that are in tourist demand. From a geo-referenced tourist inventory on the cartographic base provided by the Military Geographical Institute (Instituto Geográfico Militar), the characteristics of each place, tradition or event are determined that can be considered as a further attraction. Next, situational analysis is performed by applying the SWOT matrix and the viability of tourism projects based on logical framework matrix is determined. The use of multicriteria matrices allows the identification of suitable places for rural tourism attractions and the central place theory allows the organization of these attractions in districts. Research provides the basis in the process of rebuilding the tourism sector in the Pedernales canton, devastatedby the earthquake of April 16, 2016.
\end{abstract}

Keywords: Rural Tourism, Multicriteria analysis, Economic planning, Clustering, Innovation

Recibido: 24 de noviembre de 2016

Aceptado: 17 de mayo de 2017

Publicado: 31 de julio de 2017 


\section{Introducción}

En el momento actual se constatan grandes expectativas sociales en torno al turismo rural y su función dinamizadora de la economía de las zonas rurales. Expectativas no solo económicas sino también personales, de aquellos que apuestan por un sector en términos empresariales abierto, de fácil acceso y de altos niveles de crecimiento y grandes potencialidades. Así mismo se ha constatado la escasez, cuando no ausencia de estudios relativos a la empresa turística rural del Ecuador, u orientados hacia el análisis de la misma, hecho posiblemente debido a la relativa novedad en cuanto al nacimiento de esta nueva tendencia en la oferta turística y al protagonismo de otras perspectivas, especialmente las relacionadas con el sol y playa.

Dentro de este contexto, la problemática se centra en el desarrollo de una metodología integradora que permita la definición de un modelo teórico, denominado Distrito Turístico Rural que ayude y potencie a los agentes productores de este tipo de turismo, las pymes turísticas rurales. Un modelo elaborado y definido a partir de las ideas, métodos y enseñanzas de la economía de las experiencias y de clustering, orientado hacia la problemática empresarial del turismo rural que involucre de manera integral todos sus actores.

El objetivo general de este trabajo es: configurar un modelo de desarrollo para el turismo rural desde la perspectiva de la demanda denominada "Distrito Turístico Rural" basado en una aplicación de la metodología de innovación en valor y clustering.

El levantamiento de información, para esta investigación se desarrolló antes del terremoto del 16 de abril de 2016, evento de origen natural que destruyó, casi en su totalidad, el cantón Pedernales entre otras zonas del litoral ecuatoriano. De ahí la relevancia de esta investigación, que entrega un estudio que facilita los procesos de planificación y reconstrucción del sector turístico, que ha quedado devastado luego del seísmo.

\section{Aproximación al turismo rural}

Considerando las definiciones por categorías propuestas ${ }^{[1]}$ y la estructura del sector turístico en el Ecuador, la propuesta presentada en este estudio[2], la misma que permite determinar distintas tipologías de turismo rural, fundamentadas en las "Líneas de Productos y Variedades de Productos Específicos del Ecuador" ${ }^{[2]}{ }^{[3]}$ concibe este tipo de turismo como: "aquella actividad turística realizada en el espacio rural compuesta por una oferta integrada de ocio, dirigida a una demanda cuya motivación es el contacto con el entorno autóctono, es decir naturaleza, gastronomía, arquitectura tradicional, folklore y tradiciones populares, y que presente una interrelación con la sociedad local", dentro de este contexto, la actividad turística rural puede segmentarse en múltiples subproductos.

\section{El Proceso Planificador del Turismo Rural}

La planificación del turismo rural debe buscar el equilibrio entre el bienestar de los territorios y/o comunidades rurales y la satisfacción de los turistas, de allí que la planificación turística debe construirse en función de un análisis de entorno y una evaluación del potencial turístico territorial. Se considera que todo tipo de planificación en el campo del turismo rural, debe ser sustentable, integrada a la planificación de territorio, de carácter participativo y fundamentada en un compromiso entre los actores sociales y políticos de las circunscripciones territoriales ${ }^{[1]}$.

\section{El proceso de planificación económica del turismo.}

La planificación económica del turismo no es una actividad que se realice periódicamente, sino una actividad permanente que integra una serie de fases que interactúan constantemente y de forma dinámica ${ }^{[4]}$, considerando este planteamiento teórico se puede identificar las siguientes fases: diagnóstico, diseño, ejecución, control y evaluación ${ }^{[5]}$.

Para la fase de diagnóstico, se utiliza métodos de análisis cuantitativos como cualitativos, matrices multicriterio, FODA y marco lógico. Herramientas que en base a datos secundarios y primarios permiten el diseño de la planificación basada en la realidad socioeconómica del territorio. Para el diseño se utiliza el análisis multicriterio[ ${ }^{[6]}$ y el modelo de innovación en valor ${ }^{[7]}$ que permiten diseñar portafolios de proyectos de turismo rural, en base a criterios que la técnica turística sugiere.

La base teórica de la planificación territorial para el turismo (fase diseño), está dada por la teoría de lugar central ${ }^{[8]}$. Si se sitúa una empresa en un lugar, este tenderá a concentrar la población y a 
servir a sus habitantes y a todo su alcance. La población más alejada tenderá a no desplazarse para adquirir ese servicio, a no ser que se acumulen consumos de servicios, y en esta área surgirán otras empresas del mismo tipo, hasta

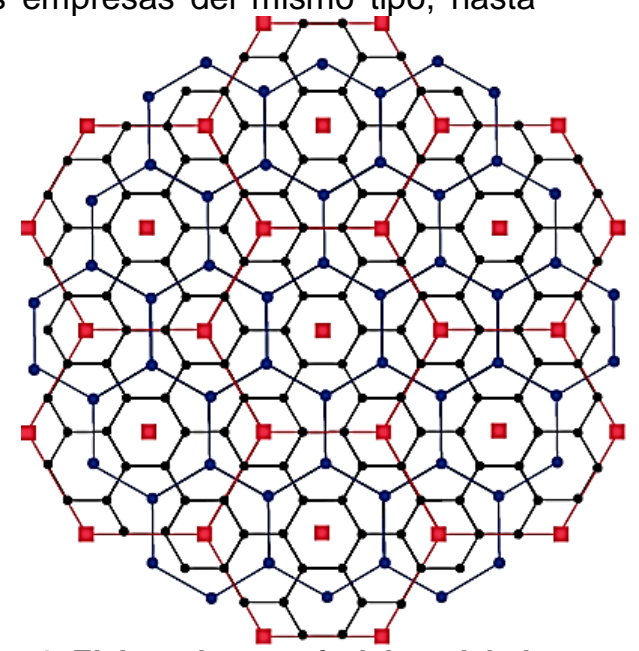

lograr un equilibrio. El área del alcance de una empresa tendrá forma hexagonal, para garantizar la prestación de ese servicio a todo el espacio isotrópico (Figura 1).

Figura 1. Elaborado a partir del modelo hexagonal centro periferia de Christaller (1966)

La función principal de una ciudad es de servir de lugar central proporcionando bienes y servicios al espacio rural que la rodea ${ }^{[8]}$. En este modelo los centros urbanos elementales están dispuestos de tal modo que todo punto del territorio rural, comercialmente abastecido no deberá estar distanciado de su centro de consumo.

La fase de ejecución se alimenta de los programas y proyectos identificados en la fase anterior y permite la elaboración de proyectos definitivos considerando las fuentes de financiamiento tanto públicas como privadas. Los resultados de la fase de ejecución son inputs de la fase de evaluación y control, que identifica las desviaciones entre lo planeado y lo ejecutado, analiza las causas y elabora recomendaciones a la fase de formulación de la estrategia de la fase diseño.

\section{Metodología}

Existe un denominador común en todos los procesos de planificación de turismo rural y es que estos empiezan a construirse a partir de la evaluación del potencial turístico territorial. Las metodologías observadas más comunes [9] [10] [11] parten del análisis de situación del sector turístico local que comprende: oferta, demanda, competencia y tendencias de mercado; con estos insumos se construye el FODA, mismo que se complementa con el análisis de involucrados que corresponde a la metodología de marco lógico.
La Metodología de Marco Lógico (MML), es una herramienta para facilitar el proceso de conceptualización, diseño, ejecución y evaluación de proyectos. Enfatiza la orientación por objetivos, la orientación hacia grupos beneficiarios, en lo fundamental, facilita la participación y la comunicación entre las partes interesadas $^{[\mathbf{1 2}]}$.

En el caso del turismo, debe considerarse que esta actividad involucra un valor intangible para el cliente, generado a través de las sensaciones y experiencias que éste experimenta al visitar un lugar determinado; las metodologías antes descritas no toman en cuenta el proceso de construcción de esa experiencia única en el diseño del producto turístico.

El diseño de los productos turísticos debe partir de dos elementos fundamentales [13]: la demanda del mercado turístico (necesidades, deseos, expectativas, características demográficas, tamaño de la demanda) y los recursos turísticos disponibles (flora y fauna, ambiente y paisaje, ríos, mar, laguna, etc.); de la combinación de estos dos aspectos se formula la idea inicial de concepto del producto.

Para el primer elemento se parte del diseño del producto turístico, evaluando factores de carácter interno relacionados con los recursos financieros, humanos y tecnológicos; además factores de carácter externo como los económicos, cultural, políticos, etc., lo que implica el uso de metodologías de análisis situacional, marco lógico e innovación en valor. 
Para el segundo elemento, se planifica el estudio de oferta en función de los requerimientos de la demanda, la misma que tiene en cuenta a los atributos (definidos por la demanda) cuya valoración es compleja; lo que configura una decisión multicriterio discreta, donde es necesario la aplicación de un modelo de agregación de preferencias en una síntesis global, ordenación, clasificación, participación, jerarquización de dichos atributos para determinar la solución que globalmente recibe las mejores evaluaciones ${ }^{\left[{ }^{6}\right]}$. Atributos que en el caso del turismo rural se centrarán a: las características eco-naturales, socio-culturales y administrativos de los diferentes territorios ${ }^{\left[{ }^{14}\right]}$.

Definidos el mercado, la demanda, y la oferta; se busca interrelacionarlos considerando la homogeneidad territorial, cultural y social de los sitios donde se ubican los atractivos ${ }^{[19]}$. Teniendo en cuenta los resultados de las matrices multicriterio y la teoría de localización se define un clúster de turismo al que se lo denomina "Distrito Turístico Rural".
El proceso metodológico propuesto para el diseño del distrito turístico rural comprende: 1. inventario de recursos turísticos, 2. análisis situacional, 3. análisis marco lógico, 4. diseño del perfil del producto turístico innovador, 5.valoración de inventarios para estructurar una oferta turística rural innovadora, 6 . determinación del distrito turístico rural basado en la metodología clustering.

\section{Análisis y resultados \\ Inventario de Atractivos Turísticos el cantón Pedernales}

En base al "Inventario de Atractivos Turísticos de la Provincia de Manabí" actualizado a 2015, a través dela investigación de campo, se verifica y define la información sobre las características y ubicaciones de los atractivos turísticos más sobresalientes.

En la Tabla 1 se presenta estos atractivos clasificados en dos categorías y jerarquizados de acuerdo a la metodología OEA.

Tabla 1. Clasificación de atractivos Pedernales - Manabí

\begin{tabular}{|ll|}
\hline Atractivos naturales & Atractivos culturales \\
\hline Playa "La Chorrera" & Feria del Queso, la cuajada y el suero blanco de \\
Playa "La Cabuya" & Atahualpa \\
Playa "Punta Palmar" & Zona Arqueológica de Santa Teresita y Atahualpa \\
Playa "Coaque" & "Historia del Sol de Oro" de Pedernales \\
Playa "Pedernales" & Proyecto Museo Corporación Santana de Pedernales \\
Punta "Los Frailes" & Proyecto Museo Familia Aguirre \\
Playa Cabeza de Vaca, Arrastradero, El Corcovado, & Encocado de corvina \\
Surrones, Casa Blanca, Juananu, Coco Solo. & Zona arqueológica de Beche abajo \\
Playa Carrizal & Festival de la corvina de Cojimíes \\
Playa Cojimíes & Escultura "El Corcovado" \\
Estuario del río Cojimíes & Bebida "Coco Loco" \\
Bosque protector "Pata de Pájaro" & Iglesia Nuestra Madre María Auxiliadora de \\
Rancho Pablito & Pedernales(En reconstrucción) \\
Cascada de Tigua & Hacienda Tachina \\
Cascada de Chindul & Zona Arqueológica de Coaque \\
Ecoturismo Río Coaza & Grupo Étnico Los Chachis \\
Río Coaque & Leyendas "El Riviel de Cojimíes" \\
Reserva Ecológica Mache - Chindul & \\
\hline
\end{tabular}

Nota: Elaborado a partir de [17], [21]

\section{Análisis situacional}

Pedernales es un polo de desarrollo turístico debido a que la naturaleza lo ha dotado de diferentes atractivos. Está atravesado por la Línea Ecuatorial, es un cantón ganadero, agrícola, camaronero y turístico; tiene un suelo accidentado y está habitado por una variada flora y fauna, sin embargo, la tasa de participación laboral global es del $44,6 \%$ y la pobreza por necesidades insatisfechas está en el 93,7\% [15], datos poco alentadores que contrastan con la riqueza de la zona.

Luego de haber realizado un análisis situacional del cantón (FODA), se obtiene la matriz síntesis, que se presenta en la Tabla 2.

\section{Evaluación marco lógico}

Complementado al análisis FODA la metodología de evaluación ex-ante de proyectos sociales (MML) incorpora la perspectiva 
comunitaria al desarrollo de programas de turismo rural, el análisis de involucrados presenta los resultados mostrados en la Tabla 3. Los elementos descritos en esta matriz, permiten integrar estrategias que atenúan potenciales conflictos entre los beneficiarios o afectados por los proyectos de turismo rural.

Tabla 2. Matriz estratégica FODA

\begin{tabular}{|c|c|c|}
\hline & $\begin{array}{l}\text { Fortalezas } \\
\text { 1. Atractivos turísticos de buena calidad. } \\
\text { 2. Ubicación privilegiada. } \\
\text { 3. Excelentes vías de acceso. } \\
\text { 4. Voluntad política de las autoridades } \\
\text { del cantón para el desarrollo del } \\
\text { turismo como actividad económica } \\
\text { base. }\end{array}$ & $\begin{array}{l}\text { Debilidades } \\
\text { 1. Altos índices de pobreza en el } \\
\text { cantón Pedernales. } \\
\text { 2. } \begin{array}{l}\text { Economía dependiente la pesca del } \\
\text { camarón. }\end{array} \\
\text { 3. Personal poco capacitado en el } \\
\text { sector turístico. } \\
\text { 4. No contar con planificación urbana } \\
\text { que favorezca el ornato de la ciudad } \\
\text { de Pedernales. } \\
\text { 5. } \begin{array}{l}\text { Débil relaciones entre terratenientes } \\
\text { y comunidades rurales. }\end{array}\end{array}$ \\
\hline $\begin{array}{l}\text { Oportunidades } \\
\text { Políticas de gobierno que apoyan } \\
\text { el desarrollo del turismo rural } \\
\text { comunitario. } \\
\text { Tendencia hacia el turismo de } \\
\text { naturaleza. } \\
\text { Programas estatales de } \\
\text { financiamiento para iniciativas } \\
\text { comunitarias en el ámbito del } \\
\text { turismo rural. } \\
\text { Creación de la ruta turística del } \\
\text { Spondylus. }\end{array}$ & $\begin{array}{l}\text { - Considerando los atractivos turísticos } \\
\text { que presenta el cantón desarrollar } \\
\text { programas que permitan optimizar la } \\
\text { visita del turista, incluyendo como } \\
\text { base fundamental la naturaleza. } \\
\text { - Generar proyectos de desarrollo } \\
\text { turístico que involucre a las } \\
\text { comunidades rurales del cantón y a los } \\
\text { gobiernos seccionales. } \\
\text { Activar al cantón Pedernales como } \\
\text { punto de importancia en las rutas y } \\
\text { circuitos turísticos nacionales. }\end{array}$ & 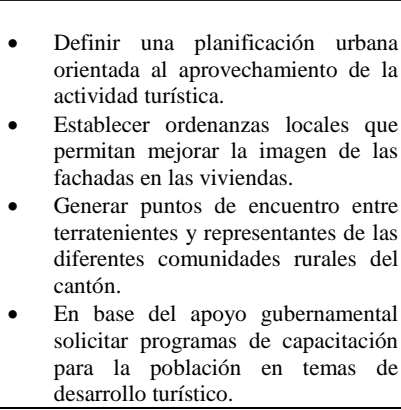 \\
\hline $\begin{array}{l}\text { Amenazas } \\
\text { Aumento de los índices de } \\
\text { inseguridad. } \\
\text { Aumento sostenido de la tasa de } \\
\text { inflación. } \\
\text { Crisis económica mundial que ha } \\
\text { afectado al turismo receptivo. } \\
\text { Incrementos decrecientes del PIB } \\
\text { del Ecuador. } \\
\text { Aumento de la migración }\end{array}$ & $\begin{array}{l}\text { - Con el apoyo de los gobiernos } \\
\text { seccionales y las comunidades } \\
\text { desarrollar programas de seguridad } \\
\text { comunitaria. } \\
\text { Establecer programas turísticos } \\
\text { innovadores de sol, playa y ecoturismo } \\
\text { con precios competitivos. } \\
\text { Desarrollar programas de turismo rural } \\
\text { comunitario que promueva la } \\
\text { economía endógena y que contribuya a } \\
\text { la disminución de los índices de } \\
\text { migración. }\end{array}$ & $\begin{array}{l}\text { - Diversificación de las fuentes de } \\
\text { ingreso económico del cantón. } \\
\text { - Promover proyectos de } \\
\text { mejoramiento urbano que permita } \\
\text { elevar las condiciones de vida de las } \\
\text { comunidades rurales. }\end{array}$ \\
\hline
\end{tabular}

Nota: Matriz diseñada antes de la ocurrencia del terremoto de 2016

Tabla 3. Análisis de involucrados del Cantón Pedernales - Metodología Marco Lógico

\begin{tabular}{|c|c|c|c|c|}
\hline Involucrados & $\begin{array}{c}\text { Interés respecto al } \\
\text { proyecto }\end{array}$ & Problemas percibidos & Recursos y mandatos & Conflictos potenciales \\
\hline $\begin{array}{l}\text { Población de las } \\
\text { zonas rurales. }\end{array}$ & $\begin{array}{l}\text { Mejorar sus condiciones } \\
\text { de vida. }\end{array}$ & $\begin{array}{l}\text { Altos niveles de pobreza. } \\
\text { Bajos niveles de educación. }\end{array}$ & $\begin{array}{l}\text { Propietarios de tierras con } \\
\text { potencial turístico rural. }\end{array}$ & $\begin{array}{l}\text { Resistencia a complementar la } \\
\text { actividad agrícola con actividades } \\
\text { de turismo rural. }\end{array}$ \\
\hline $\begin{array}{l}\text { Gobierno } \\
\text { Municipal. } \\
\text { Promotor del } \\
\text { proyecto. }\end{array}$ & $\begin{array}{l}\text { Fomentar el desarrollo } \\
\text { económico y social de la } \\
\text { población. } \\
\text { Mejoramiento de las } \\
\text { condiciones de vida. }\end{array}$ & $\begin{array}{l}\text { Imposibilidad de mejorar las } \\
\text { condiciones de vida de la } \\
\text { población. }\end{array}$ & $\begin{array}{l}\text { Capacidad de toma de } \\
\text { decisiones en el ambiente } \\
\text { público. }\end{array}$ & $\begin{array}{l}\text { Dependiente del apoyo de la } \\
\text { comunidad y los líderes de los } \\
\text { sectores sociales y parroquiales. }\end{array}$ \\
\hline $\begin{array}{l}\text { Asociación de } \\
\text { Hoteleros de }\end{array}$ & $\begin{array}{l}\text { Posible disminución de los } \\
\text { ingresos por aumento de la } \\
\text { oferta turística }\end{array}$ & $\begin{array}{l}\text { Disminución de ingresos por } \\
\text { aumento de oferta turística. }\end{array}$ & $\begin{array}{l}\text { Influencia política para } \\
\text { boicotear el proyecto. }\end{array}$ & $\begin{array}{l}\text { Conflictos con el gobierno municipal } \\
\text { del cantón. }\end{array}$ \\
\hline $\begin{array}{l}\text { Juntas } \\
\text { parroquiales } \\
\text { rurales. }\end{array}$ & $\begin{array}{l}\text { Aumentar el bienestar de } \\
\text { la población y provisión de } \\
\text { servicios. }\end{array}$ & $\begin{array}{l}\text { Dificultades para mejorar el } \\
\text { bienestar de la población. } \\
\text { Conflictividad política entre la } \\
\text { Junta parroquial y el } \\
\text { Municipio Cantonal. }\end{array}$ & $\begin{array}{l}\text { Capaz de ejecutar órdenes } \\
\text { administrativas y de } \\
\text { asuntos públicos. } \\
\text { Administrador de la justicia } \\
\text { y asuntos públicos. }\end{array}$ & $\begin{array}{l}\text { Bloquear las acciones del proyecto } \\
\text { por discrepancias políticas. } \\
\text { Con el Alcalde del cantón si permite } \\
\text { el in-greso de mano de obra foránea } \\
\text { para la imple-mentación del } \\
\text { poyecrto. }\end{array}$ \\
\hline $\begin{array}{l}\text { Terratenientes de } \\
\text { zonas rurales }\end{array}$ & $\begin{array}{l}\text { Mejorar el valor de sus } \\
\text { tierras. }\end{array}$ & $\begin{array}{l}\text { Sentimiento de amenaza de } \\
\text { expropiación. } \\
\text { Pérdida de mano de obra } \\
\text { barata para el trabajo } \\
\text { agrícola. }\end{array}$ & $\begin{array}{l}\text { Poder económico que } \\
\text { puede ser utilizado para } \\
\text { influir en el sistema estatal. }\end{array}$ & $\begin{array}{l}\text { Oponerse al proyecto amenazados } \\
\text { por las expropiaciones y la pérdida } \\
\text { de mano de obra barata para sus } \\
\text { tierras. }\end{array}$ \\
\hline Turistas & $\begin{array}{l}\text { Disfrutar de una nueva } \\
\text { opción turística en el } \\
\text { cantón Pedernales. }\end{array}$ & $\begin{array}{l}\text { Insuficiente infraestruc-tura } \\
\text { turística en zonas rurales del } \\
\text { cantón Pedernales. }\end{array}$ & $\begin{array}{l}\text { Recursos financieros } \\
\text { Pueden elegir otros } \\
\text { lugares de destino turístico }\end{array}$ & $\begin{array}{l}\text { Conflictos con los prestadores de } \\
\text { servicios turísticos rurales si no } \\
\text { cubren las expectativas exigidas. }\end{array}$ \\
\hline
\end{tabular}




\section{Definición del producto turístico basada en innovación de valor}

Para incorporar la innovación en valor, se realiza un estudio de atributos con la aplicación de matrices multicriterio ${ }^{[6][22]}$. Este método comprende la selección entre un conjunto de alternativas factibles, la optimización con varias funciones objetivos simultáneamente, un agente decisor y procedimientos de evaluación racionales y consistentes, como se puede visualizar, los factores (críticos, importantes y de menor relevancia) son la base para la construcción del "Distrito Turístico Rural". Estos elementos de calificación se presentan en la Tabla 4.

Tabla 4.Conformación del distrito rural

\begin{tabular}{|c|c|c|c|}
\hline $\begin{array}{l}\text { FACTORES PARA CALIFICAR COMO DESTINO } \\
\text { TURISTICO RURAL COMUNITARIO }\end{array}$ & $\begin{array}{c}\text { Importancia } \\
\text { por grupo de } \\
\text { factores }\end{array}$ & $\begin{array}{l}\text { Importancia } \\
\text { total }\end{array}$ & \\
\hline Agua & $21,60 \%$ & $6,75 \%$ & \multirow{7}{*}{ 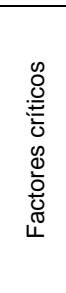 } \\
\hline Paisaje & $18,12 \%$ & $5,66 \%$ & \\
\hline Contribución del turismo al desarrollo local & $25,52 \%$ & $5,58 \%$ & \\
\hline Apropiación y valoración de atractivos & $25,52 \%$ & $5,58 \%$ & \\
\hline Importancia relativa con el entorno geográfico regional & $11,58 \%$ & $5,43 \%$ & \\
\hline Integración con comunidades vecinas & $23,63 \%$ & $5,17 \%$ & \\
\hline Administración y dirección & $10,81 \%$ & $5,07 \%$ & \\
\hline Grado de organización comunitaria & $9,95 \%$ & $4,67 \%$ & \multirow{17}{*}{ 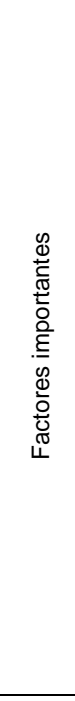 } \\
\hline Seguridad para el turista & $9,49 \%$ & $4,45 \%$ & \\
\hline Políticas y planificación & $9,46 \%$ & $4,44 \%$ & \\
\hline Energía & $13,67 \%$ & $4,27 \%$ & \\
\hline Accesibilidad & $8,92 \%$ & $4,18 \%$ & \\
\hline Liderazgo & $8,84 \%$ & $4,15 \%$ & \\
\hline Manejo de áreas naturales & $12,35 \%$ & $3,86 \%$ & \\
\hline Diferenciación del producto turístico & $7,20 \%$ & $3,37 \%$ & \\
\hline Especies de flora de interés turístico & $10,62 \%$ & $3,32 \%$ & \\
\hline Especies de fauna de interés turístico & $10,62 \%$ & $3,32 \%$ & \\
\hline Conservación Patrimonio Histórico-Cultural & $13,55 \%$ & $2,96 \%$ & \\
\hline Diversificación de la oferta de servicios & $5,75 \%$ & $2,69 \%$ & \\
\hline Diseño y construcción & $4,53 \%$ & $2,12 \%$ & \\
\hline Intervención externa & $4,29 \%$ & $2,01 \%$ & \\
\hline Manejo de desechos & $6,19 \%$ & $1,93 \%$ & \\
\hline Percepción de la calidad & $3,40 \%$ & $1,59 \%$ & \\
\hline Capacitación & $3,13 \%$ & $1,47 \%$ & \\
\hline Artesanía & $5,50 \%$ & $1,20 \%$ & \multirow{8}{*}{ 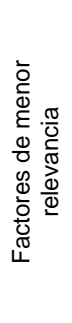 } \\
\hline Aguas servidas & $2,87 \%$ & $0,90 \%$ & \\
\hline Educación ambiental & $2,57 \%$ & $0,80 \%$ & \\
\hline Gastronomía & $3,56 \%$ & $0,78 \%$ & \\
\hline Presión de la demanda turística en los recursos & $1,62 \%$ & $0,76 \%$ & \\
\hline Festividades & $2,74 \%$ & $0,60 \%$ & \\
\hline Promoción y comercialización & $1,04 \%$ & $0,49 \%$ & \\
\hline Calidad de senderos & $1,39 \%$ & $0,43 \%$ & \\
\hline
\end{tabular}

Considerando estos factores de calificación para el distrito turístico rural, se procede a valorar el inventario de atractivos y se los jerarquiza en función de su aptitud (grado de asociación con los factores de calificación) resultado de ello se obtiene la Tabla 5.

La valoración de los atractivos, permite el diseño de rutas turísticas (productos turísticos), teniendo en cuenta su optimización, ubicación y homogeneidad socio cultural, aspectos señalados por el modelo centro periferia ${ }^{[8]}$.
En base a estos planteamientos, se considera los criterios de valoración de proyectos de turismo rural[16][19] como: costo, adaptación del entorno natural, adaptación del entorno sociocultural, impacto en el desarrollo local, promoción de género, generación de empleo, equidad, aptitud como destino de turismo comunitario. Considerando los atractivos de mayor aptitud tenemos como resultado del estudio multicriterio, la matriz de impacto de la Tabla 6. 
Tabla 5.Valoración de atractivos por aptitud para Turismo Rural

\begin{tabular}{|c|c|c|c|}
\hline Atractivo turístico & Parroquia & Índice & \\
\hline Reserva Ecológica Mache Chindul & Todas & 8,54 & ALTA APTITUD \\
\hline Festival de la Corvina en Cojimíes & Cojimíes & 8,50 & ALTA APTITUD \\
\hline Ecoturismo Río Coaza & Cojimíes & 8,13 & ALTA APTITUD \\
\hline Playa "Pedernales" & Pedernales & 7,70 & ALTA APTITUD \\
\hline Finca agroturística II Peperoncino & Pedernales & 7,65 & ALTA APTITUD \\
\hline Bosque protector "Pata de Pájaro" & Atahualpa & 7,54 & ALTA APTITUD \\
\hline Feria del Queso, la cuajada y el suero blanco de Atahualpa & Atahualpa & 7,25 & MEDIANA APTITUD \\
\hline Playa Cojimíes & Cojimíes & 7,25 & MEDIANA APTITUD \\
\hline Grupo Étnico Los Chachis & Cojimíes & 7,22 & MEDIANA APTITUD \\
\hline Estuario del Río Cojimíes & Cojimíes & 7,04 & MEDIANA APTITUD \\
\hline Encocado de corvina & Cojimíes & 6,96 & MEDIANA APTITUD \\
\hline Rancho Pablito & Cojimíes & 6,60 & MEDIANA APTITUD \\
\hline Proyecto Museo Familia Aguirre & Pedernales & 6,43 & MEDIANA APTITUD \\
\hline Zona Arqueológica de Santa Teresita y Atahualpa & Atahualpa & 6,37 & MEDIANA APTITUD \\
\hline Proyecto Museo Corporación Santana de Pedernales & Pedernales & 6,36 & MEDIANA APTITUD \\
\hline Zona Arqueológica de Coaque & Pedernales & 6,26 & MEDIANA APTITUD \\
\hline Playa Cabeza de Vaca, Arrastradero, El Corcovado, Surrones, Casa Blanca, Juananu, Coco Solo. & Pedernales & 6,20 & MEDIANA APTITUD \\
\hline Cascada de Chindul & Pedernales & 6,03 & MEDIANA APTITUD \\
\hline Playa "Coaque" & Pedernales & 5,95 & MEDIANA APTITUD \\
\hline Hacienda Tachina & Pedernales & 5,94 & MEDIANA APTITUD \\
\hline Iglesia Nuestra Madre María Auxiliadora de Pedernales & Pedernales & 5,88 & MEDIANA APTITUD \\
\hline Zona arqueológica de Beche abajo & Cojimíes & 5,84 & MEDIANA APTITUD \\
\hline Río Coaque & Pedernales & 5,83 & MEDIANA APTITUD \\
\hline Cascada de Tigua & Cojimíes & 5,78 & MEDIANA APTITUD \\
\hline Playa "La Cabuya" & Pedernales & 5,45 & MEDIANA APTITUD \\
\hline Playa "La Chorrera" & Pedernales & 5,05 & MEDIANA APTITUD \\
\hline Bebida "Coco Loco" & Pedernales & 4,69 & MEDIANA APTITUD \\
\hline Playa "Punta Palmar" & Pedernales & 4,62 & MEDIANA APTITUD \\
\hline Playa Carrizal & Cojimíes & 4,02 & BAJA APTITUD \\
\hline Escultura "El Corcovado" & Pedernales & 3,67 & BAIA APTITUD \\
\hline Punta "Los Frailes" & Pedernales & 3,56 & BAIA APTITUD \\
\hline “Historia del Sol de Oro" de Pedernales & Pedernales & 2,19 & BAIA APTITUD \\
\hline Leyendas "El Riviel de Cojimíes" & Cojimíes & 2,14 & BAJA APTITUD \\
\hline
\end{tabular}

Tabla 6.Matriz de impacto y priorización de objetivos

\begin{tabular}{|c|c|c|c|c|c|c|c|c|c|c|c|c|}
\hline & & & 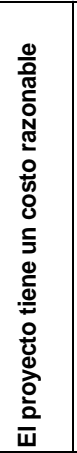 & 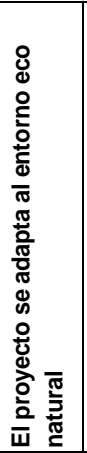 & 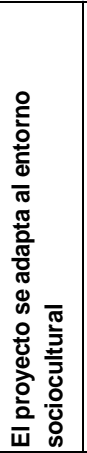 & 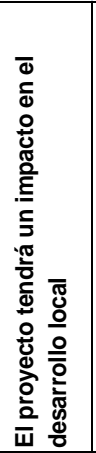 & 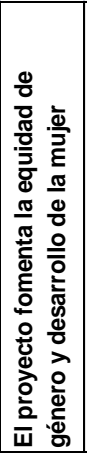 & 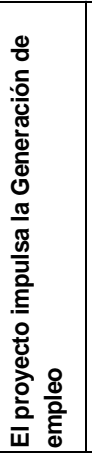 & 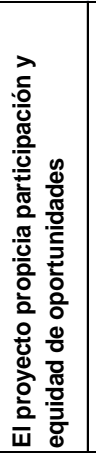 & 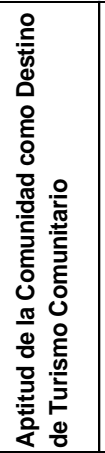 & . & \\
\hline & & & $5,80 \%$ & $8,71 \%$ & $8,48 \%$ & $20,09 \%$ & $8,26 \%$ & $16,74 \%$ & $15,85 \%$ & $16,07 \%$ & 1,000 & \\
\hline Prioridad & Parroquia & Proyecto & & & & & & & & & & Impacto \\
\hline 1 & Cojimíes & Reserva Mache - Chindul & 5 & 10 & 10 & 8 & 8 & 5 & 8 & 6,32 & 7,40 & Alto \\
\hline 2 & Pedernales & Pedernales sol y playa & 10 & 4 & 5 & 9 & 5 & 8 & 8 & 5,53 & 7,07 & Medio \\
\hline 3 & Pedernales & Ruta sol, playa y aventura. & 5 & 5 & 5 & 8 & 8 & 10 & 5 & 5,92 & 6,84 & Medio \\
\hline 4 & Cojimíes & Ecoturismo Coaza & 5 & 10 & 9 & 9 & 5 & 5 & 5 & 6,32 & 6,79 & Medio \\
\hline 5 & Cojimíes & Pesca deportiva, sol y playa & 3 & 8 & 8 & 6 & 5 & 7 & 8 & 6,32 & 6,62 & Medio \\
\hline 6 & Atahualpa & Ecoaventura & 5 & 10 & 8 & 8 & 8 & 2 & 5 & 6,29 & 6,25 & Bajo \\
\hline 7 & Pedernales & Agroturismo & 10 & 10 & 6 & 5 & 8 & 5 & 5 & 5,53 & 6,14 & Bajo \\
\hline
\end{tabular}


Para la fase de promoción y comercialización de los proyectos turísticos en cada uno de los distritos identificados (Figura 2), debe considerarse las siguientes características: accesibilidad, proximidad a centros urbanos de interés turístico, diversificación de líneas de productos turísticos, existencia de facilidades turísticas, nivel de articulación interna y externa, visitación, percepción de calidad de gestión turística, imagen y posicionamiento y apoyo institucional, el resultado de la aplicación del estudio multicriterio define la siguiente jerarquía:
Tabla 7. Distritos turísticos rurales de alta prioridad

\begin{tabular}{|l|l|}
\hline Cojimíes & 7,54 \\
\hline Mache Chindul & 6,73 \\
\hline La Cabuya (II Peperoncino) & 5,20 \\
\hline Atahualpa & 5,16 \\
\hline
\end{tabular}

Los valores finales, permiten establecer en qué distritos turísticos es necesario generar estrategias agresivas de promoción y comercialización ${ }^{[20]}$, que los posicionen en los segmentos de mercados identificados.

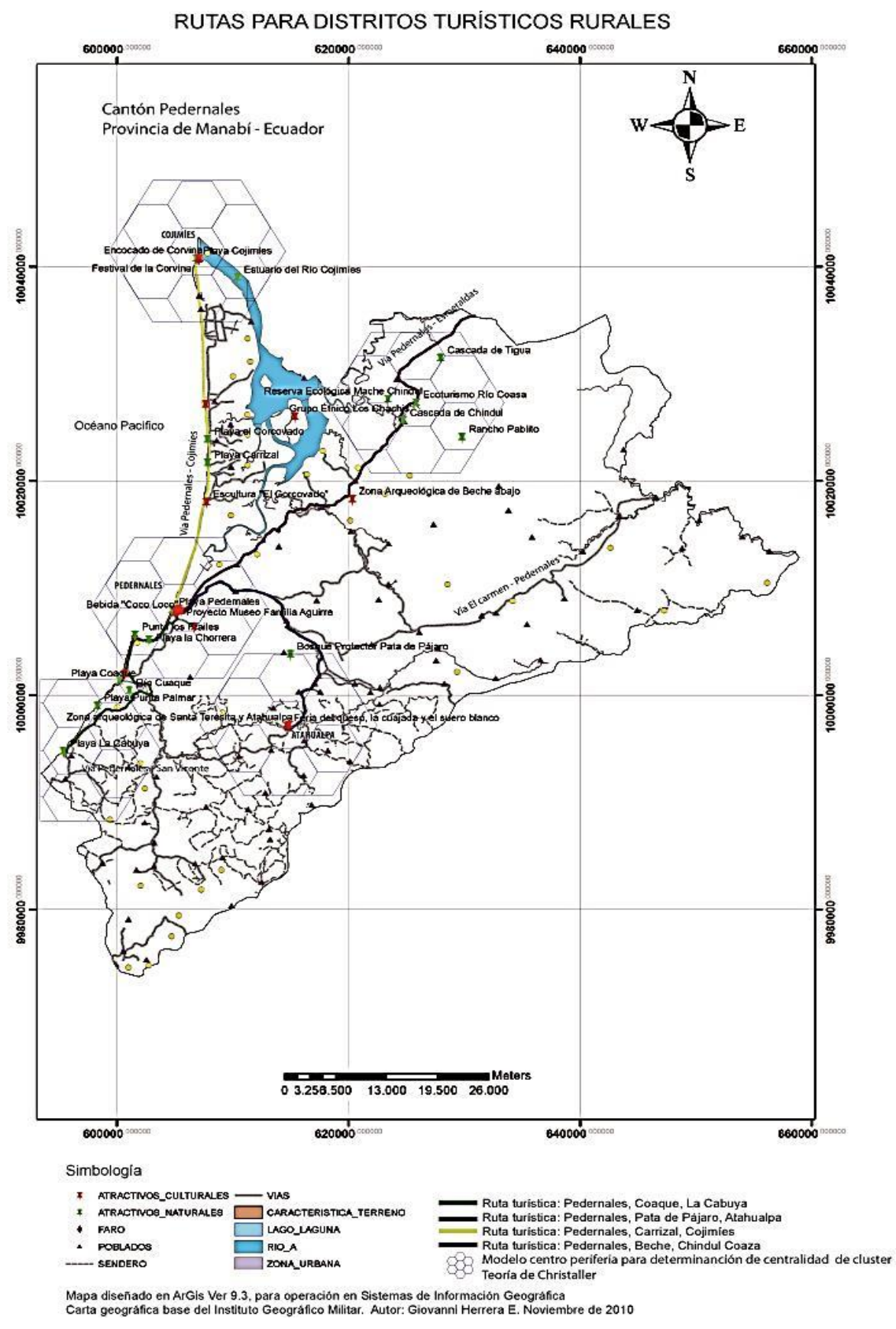

Figura 2. Rutas para turismo rural en el cantón Pedernales, en base análisis territorial. 


\section{Conclusiones}

Un adecuado desarrollo del turismo, requiere de productos bien definidos, de un sistema de calidad consolidado, de una población empoderada, capacitada y consciente de que el bien colectivo está sobre el individual, de gobiernos locales comprometidos que impulsen a través de políticas innovadoras mejoraras en la infraestructura básica, en la planificación urbana y en la organización comunitaria.

La tarea de promoción turística, es un esfuerzo coordinado, que incluye a varios actores, el estado en diferentes niveles - central, provincial, municipal; empresarios privados, comunidades, ONG, universidades, incluso los mismos turistas, se incluye en estos procesos las políticas de generarles de desarrollo, la actualización de inventarios, la promoción y difusión de los destinos y un permanente procesos de capacitación a las ciudades y comunidades involucradas.

La pérdida de valor es uno de los principales obstáculos en la relación turismo - desarrollo. Para evitar o minimizar el efecto de las fugas de valor, es necesario aplicar modelos de innovacióny clustering sobre la base de la planificación local-territorial, creando entornos favorables a la producción turística por parte de las instituciones, las comunidades y las empresas, construyendo así cadenas de proveedores - suministradores locales.

Cuanto más amplia es la dimensión de clúster, más abstracta es su definición espacial, razón por la cual la definición de productos turísticos tiene que circunscribirse en territorios pequeños, para este cometido, la teoría de Christaller, permite definir una zona central base $y$ poblaciones que con características homogéneas participan como puntos geográficos de apoyo para el desarrollo de la actividad turística.

El cluster turístico, tiene como finalidad la retención y generación de valor en el territorio donde se realiza la producción turística, a partir del despliegue a lo largo de todo el sistema de valor de cadenas de proveedores locales, a esto se denomina "Distrito Turístico Rural". Sin embargo, las actividades de promoción y comercialización deben estar ancladas a redes externas que permitan su fácil y eficiente difusión.

Se han identificado y priorizado 7 proyectos que permitirían a las comunidades convertirse en centros de turismo rural exitosos. Los proyectos se pueden clasificar principalmente en grandes ejes de acción tales como: capacitacióneducación, mejoramiento de infraestructura, equipamiento, fortalecimiento comunitario, conservación eco natural, revalorización de identidad y cultura. Estos proyectos están repartidos geográficamente y se refieren a diversas áreas de desarrollo.

\section{Referencias}

[1] Calderón, F. (2005), Distrito Turístico Rural una Modelo Teórico desde la Perspectiva de la Oferta. Especial referencia al caso Andaluz. Málaga: Tesis doctoral de la Universidad de Málaga.

[2] Fuentes, R. (1995). "El turismo rural en España. Especial referencia al análisis de la demanda" Madrid.

[3] BID (2009), PLANDETUR 2020. Quito: Ministerio de Turismo del Ecuador.

[4] Bote, V. (2002).Planificación Económica del Turismo. México D.F: Trillas, 2002.

[5] Garrido, M.. (2008) Slideshare. [Online]. http://www.slideshare.net/nikacanika/planifi cacion-fases-presentation

[6] Saaty, T. (19080).The Analytic Hierarchy Process. New York: McGraw Hill.

[7] Kim, Ch. y Mauborgne, R. (2008)La Estrategia de Océano Azul. Colombia: Norma.

[8] Christaller, W. (1966).Central places in southem Germany.: Prentice Hall.

[9] LEADER II, Evaluar el potencial turístico de un territorio. (1996): http://ec.europa.eu/agriculture/rur/leader2/r ural-es/biblio/touris/metho.pdf.

[10] GTZ (1999). Sustainable tourism as a development option. Esborn: https://www.giz.de/expertise/downloads/entourism-sustainable-development.pdf.

[11] AFIT-LEADER (2000), La valorización del turismo de senderismo en los territorios rurales.

http://ec.europa.eu/agriculture/rur/leader2/r ural-es/biblio/walking/walking.pdf.

[12] Ortegón, E.; Pacheco, J. y Prieto, A. (2005)Metodología del marco lógico apara la planificación, el seguimiento y la evaluación de proyectos y programas. 
Santiago de Chile: CEPAL, julio 2015. [Online].

http://www.extension.uner.edu.ar/adjuntos/ documentos/manual\%2042\%20ILPES\%20 MML.pdf

[13] Bravo, Y.; Partido, D.; Pérez, R. y Leyva, A. (2009). El despliegue de la función calidad en el diseño de productos turísticos con atractivos rurales. TURyDES. http://www.eumed.net/rev/turydes/05/.

[14] Rain Forest Alliance (2007).Juego de Herramientos para promover el Turismo Sostenible en América Latina. Costa Rica: Rain Forest Alliance.

[15] SIISE. (2010) Sistema de Indicadores Sociales del Ecuador. [Online]. http://www.siise.gob.ec/siiseweb/

[16] Vera, F.Planificación y Gestión de Desarrollo Turístico Sostenible: Propuestas para la creación de un sistema de indicadores. Documento de Trabajo. Alicante: Universidad de Alincante, 2001.
[17] Ministerio de Turismo (2009). PLANDETUR 2020, Quito: MINTUR

[18] SENPLADES (2014).Plan Nacional de Desarrollo. Quito: Gobierno de la República del Ecuador.

[19] Salguero, J. (2006). Enfoques sobre algunas Teorías referentes al Desarrollo Regional. Bogotá.

[20] Porter, M (2003). Estrategia Competitiva Técnicas para el Análisis de los Sectores Insdutriales y de la Competencia. México D.F.: CECSA.

[21] OEA (2004).Metodología para Inventarios de Atractivos Turísticos.

[22] Coello, F., Cevallos, R., Moscoso, F., López, P., Martinez, C., \& Ponce, L. (2008). Creación de un Portafolio de Proyectos de Turismo Comunitario. Quito: PUCE. 